\title{
Hydatid Cystic Disease of Lumbar Paraspinal Muscles
}

\author{
Waqar Alam¹, Faaiz Ali Shah*2 and Mian Amjad Ali ${ }^{3}$ \\ ${ }^{1}$ District Orthopedics Specialist, District Headquarter Hospital Temargara Lower Dir, Pakistan \\ ${ }^{2}$ Assistant Professor Orthopedics \& Trauma, Lady reading Hospital Peshawar, Pakistan \\ ${ }^{3}$ Associate Professor Orthopedics \& Trauma Unit B, Lady reading Hospital Peshawar, Pakistan
}

Received: October 28,2017; Published: November 03, 2017

*Corresponding author: Faaiz Ali Shah, MBBS,FCPS (Orthopedics), Assistant Professor, Orthopedics \& Trauma, Lady reading Hospital Peshawar, KP, Pakistan, Tel: +923349125394; Email: faaizalishah@yahoo.com

\section{Introduction}

The larva of the tap worm Echinococcus Granulosus causes Hydatid Cystic disease in humans which is a common public health problem in many countries of the Middle east, Mediterranean, Australia and New Zealand [1,2]. The cyst of the tapworm can be found anywhere in the body but liver (55 to 70\%) and lungs (20 to $30 \%$ ) are more commonly affected by the tape worm.1 The viscera of the body like heart, kidneys, spleen and brain and are very rarely affected by the disease and even rarer are the skeletal muscles which are affected in only 1 to $4 \%$ of the cases [3]. We present a case report of hydatid disease which involved the paraspinal muscles of the lumbar back without any involvement of liver or lungs.

\section{Case Report}

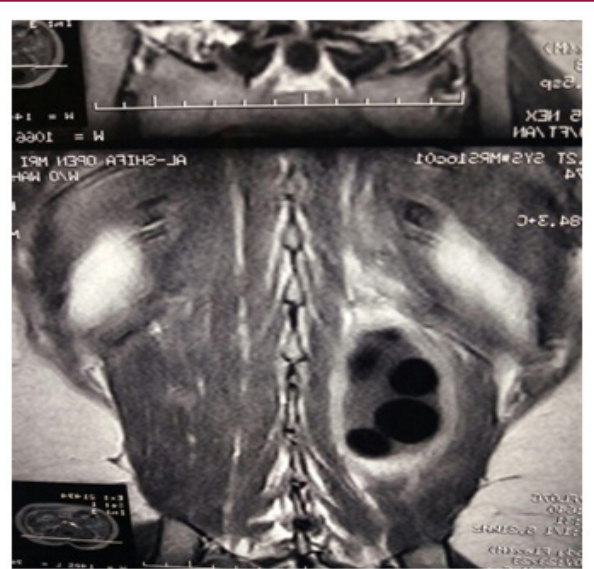

Figure 1:Sagittal MRI Lumbar area showing Multiloculated Hydatoid Cyst.

A 35 years old lady was referred by a general surgeon with chief complaints of pain and diffuses swelling on right side of par vertebral muscles in the lumbar area. She was a febrile and the swelling was not associated with any trauma. Her general health status was satisfactory. Examination reveals a diffuse and non-tender swelling in the right side of paraspinal muscles in the lumbar area. It was adherent to muscles. It was cystic in consistency. Neurological examination was normal. On blood complete examination was normal. Chest radiographs and abdominal ultrasound was normal. The diagnosis of hydatid cyst was strongly suspected on ultrasound examination, which showed multiloculated cystic mass in the para vertebral muscles in lumbar area. MRI of lumbar spine showed a multilocularis cystic lesion in the para spinal muscles on right side of lumbar area (Figures 1 \& 2). The intact intramuscular cyst was completely excised. The cavity was thoroughly irrigated with hypertonic saline. A histopathological examination confirmed hydatid cyst. Postoperatively, the patient began receiving albendazol $400 \mathrm{mg}$ twice daily, for 6 months and no recurrence reported (Figures $3 \& 4$ ).

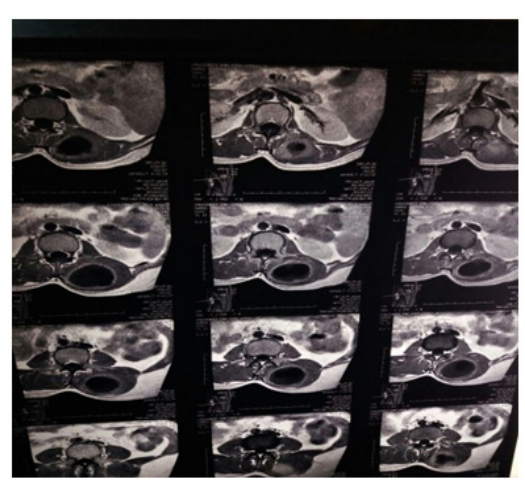

Figure 2: Coronol MRI showing Hydatoid Cyst.

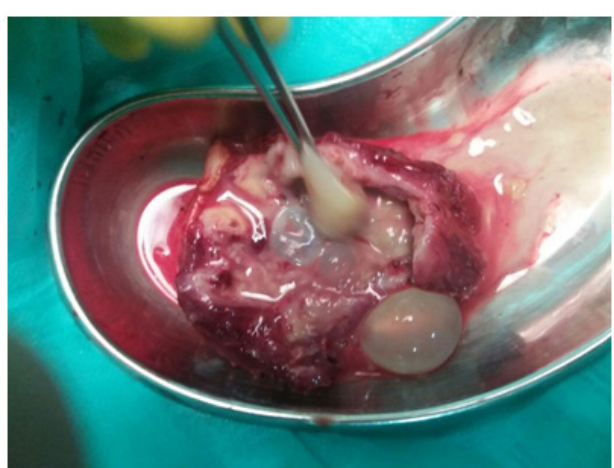

Figure 3: Hydatoid Cyst after removal through surgery. 


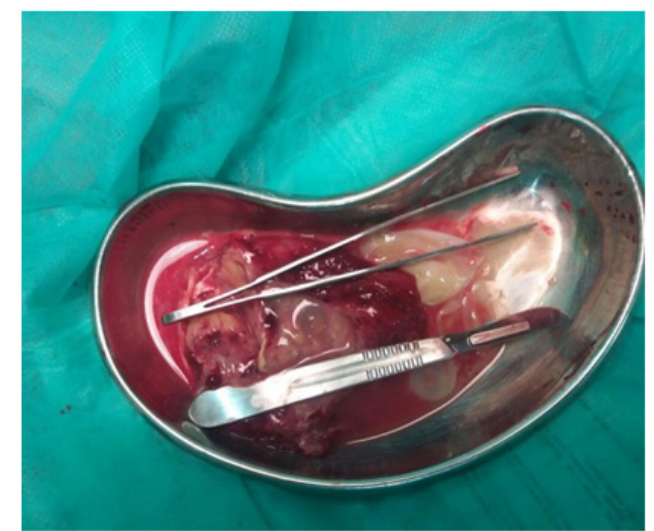

Figure 4: Hydatoid cyst after removal (approximate size).

\section{Discussion}

Hydatid cystic disease commonly known as Hydatidosis or Echinococcosis is frequently found in sheep-raising countries like Australia, Greece, South America, China and India but cases are reported in developed countries as well $[4,5]$. Humans are most commonly affected by the larva of tapeworm Echinococcus Granulosus followed by Echinococcus Multilocularis, and Echinococcus Vogeli [6,7]. The pathogenesis of Hydatid cyst in muscles is not clearly known. Various theories have been proposed. Some researchers believe that direct contact of the larva with the wound as in dog bite can be the possible explanation, while others proposed that larva is transferred to the muscles via blood stream from primary source in liver and lungs.(10 to $15 \%$ cases) [8]. Still others are of the opinion that larva is transported across the muscular layer of gut into the venous system bypassing liver $[9,10]$. Clinical features of Hydatoid cyst varies from the presence of a swelling or mass to pressure symptoms, cyst infection and rarely anaphylactic shock [1]. In our patient there was no pressure symptom except a growing mass in lower back muscles which suggests a higher suspicion of Hydatid cyst in any growing mass in muscles. The investigation of choice for diagnosing Hydatid cyst is MRI which shows a thin walled cyst with no septation and containing numerous daughter cysts inside [11] Some radiological features distinguish Hydatid cyst from other cysts and these include the "Rim sign" [12] which is a low intensity signal around the cyst," the Bunch of Grapes" sign [13] which is the hypo intense wall of the cyst on T1 and T2 images without septation and enhancement and the "Water lily sign" which denotes the detached germinal layer of the cyst wall [9].

Biochemical blood tests uses complement fixation and ELISA helps in diagnosis [14-15]. In our case the Casoni serological test was positive. Muscular Hydatid cysts are surgically removed with a wide clear margin [16]. Failure to achieve radical excision of the muscular cyst results in non-healing of wound and may require re surgery [12]. Administration of benzimidazole pre and post operatively is recommended. We were able to excise the cyst radically in our patient without any complication. Because of the difficulty of radical resection of muscular cysts and increase morbidity associated with this procedure, Biljic [17] percutaneous drain a cyst in Para spinal muscles followed by $95 \%$ ethanol injection and reported no recurrence or any complication in his 26 months follow up with this PAIR(puncture, aspiration, injection, re-aspiration) technique. However his technique is not being used in large number of patients and needs expertise as well. It is suggested that in order to prevent recurrence and complications the cyst should be removed intact but which is not always possible therefore local irrigation with formalin, aqueous iodine, silver nitrate and hypertonic solution is advocated in accidental rupture of cyst or spillage of cyst contents [13]. We recommend that hydatid cyst disease should be considered in the differential diagnosis of any lumbar muscular swelling and to confirm the diagnosis complete history, examination, serological tests and radiological investigations are necessary followed by surgical excision with wide margins to prevent recurrence.

\section{References}

1. Melis M, Marongiu L, Scintu F, Pisano M, Capra F, et al. (2002) Primary hydatid cysts of psoas muscle. Aust NZ J Surg 72: 443-445.

2. Pedrosa I, Saiz A, Arrazola J, Ferreiros J, Pedrosa CS (2000) Hydatid disease: Radiologic and pathologic features and complications. Radiographics 20:795-817.

3. Garcia Diez AI, Ros Mendoza LH, Villacampa VM, Cozar M, Fuertes MI (2000) MRI evaluation of soft tissues hydatid disease. EurRadiol 10: $462-466$.

4. Ouma JR (2006) Echinococcosis-A rare spinal disorder. S AfrMed J 96: 680-682.

5. Huizinga KT, Grant CS, Daar AS (2000) "Hydatid disease," in Oxford Textbook of Surgery, PJ Morris ,WC Wood (Eds.) pp. 3298-3305, Oxford University Press, $\left(2^{\text {nd }}\right.$ edn)

6. Kir A, Baran E (1995) Simultaneous operation for hydatid cyst of right lung and liver. Thorac Cardiovasc Surg 43: 62-64.

7. Nell M, Burgkart RH, Gradl G, Eisenhart-Rothe R, Schaeffeler C, et al. (2011) Primary extra hepatic alveolar echinococcosis of the lumbar spine and the psoas muscle. Ann ClinMicrobiolAntimicrob 10:13.

8. Manes E, Santucci A (1990) Cisti da echinococco: Localizzazione intramuscolare. ChirOrganiMov 75: 189-196.

9. Vasilevska V, Zafirovski G, Kirjas N, Janevska V, Samardziski M, et al. (2007) Imaging diagnosis of musculoskeletal hydatid disease. Prilozi 28: 199-209.

10. Sener RN, Calli C, Kitis O, Yalman O (2001) Multiple primary spinalparaspinal hydatid cysts. EurRadiol11: 2314-2316.

11. Fahl M, Haddad FS, Huballah M, Kanaan S, Husheimi I, et al. (1994) Magnetic resonance imaging in intradural and extradural spinal echinococcosis. Clin Imaging 18: 179-183.

12. Garcia-Alvarez F, Torcal J, Salinas JC, Navarro A, Garcia-Alvarez I, et al. (2002) Musculoskeletal hydatid disease: A report of 13 cases. ActaOrthopScand 73: 227-231.

13. Mirhoseini SA, Ahmadi J (2005) An unusual case of hydatid cyst. JMSR 10: $107-111$.

14. Gupta R, Mathur SR, Agarwala M, Kaushal, Srivastav (2008) Primary soft tissue hydatidosis: aspiration cytological diagnosis in two cases. DiagnCytopathol 36: 884-886.

15. Normelli HC, Aaro SI, Follin PH (1998) Vertebral hydatid cyst infection (Echinococcus granulosus): a case report. Eur Spine J 7: 158-161.

16. Ozdemir HM, Ogün TC, Tasbas B (2004) A lasting solution is hard to achieve in primary hydatid disease of the spine: long-term results and an overview. Spine 29: 932-937. 
17. Bilgic S, Kose O, Sehirlioglu A, Ismail Safaz I, Ozkan H (2009) Primary paraspinal hydatid cyst treated with puncture, aspiration, injection and re-aspiration (PAIR) technique: A case report. Eur Spine J 18(Suppl 2): 165-167.

$\begin{array}{ll}\text { BIOMEDICAL } & \text { Assets of Publishing with us } \\ \text { RESEARCHES } & \text { Global archiving of articles } \\ & \text { - Immediate, unrestricted online access } \\ \end{array}$

